\title{
MONETISATION OF PROJECT FOOD AID?
}

\section{Jens Schulthes}

\section{INTRODUCTION: IN SEARCH OF MORE ROOM FOR MANOEUVRE 1}

For decades, the debate on monetisation of project food aid seemed closed: commodity sales and programming of counterpart funds (the term 'monetisation' is of recent origin) were looked upon as the attempt by project food aid agencies to break out of their narrow mandate - mostly vulnerable group feeding and foodfor-work - into a broader range of mainstream development activities which required cash to be obtained through open market sales; hence, the tendency of major food aid donors to guard monetisation jealously for their own bilateral programmes - in the case of WFP, donors agreed reluctantly to a level of monetisation of 15 per cent of total deliveries. ${ }^{2}$

This is now changing - the potential of monetisation as a means of targeting food aid to food-insecure households is beginning to attract attention, and project food aid agencies are invited to develop it, perhaps a little more audaciously than they would themselves prefer. This came out strongly in the study of the role of food aid in Africa which the World Bank and WFP undertook jointly during 1989/90, and which turned into a protracted effort because the World Bank wished to see far higher emphasis put on monetisation than WFP was ready to accept (World Bank/WFP 1991). WFP has so far decided to remain within its traditional level of monetisation of 15 per cent. However, at the IDS workshop on 'Commodity Aid and Counterpart Funds in Africa' in January 1991, I proposed a set of practical criteria which I thought would help agencies like my own to choose between monetisation and distribution in kind in the individual case. These were modified and adopted by the workshop (Maxwell and Owens 1991:21) and are reproduced with further minor changes in Figure 1.

However, the checklist did not reckon with certain key concerns of project food aid managers. This Bulletin article will address these in greater detail. It will argue the continuing merits and legitimacy of food distribution in kind up to a point: if food aid is to play a more effective role in targeted alleviation of household food insecurity, then the traditional approach is too limited and monetisation can open up new room for manoeuvre.

\section{THREE KEY CONSTRAINTS - THREE MAJOR CHALLENGES}

Monetisation meets with three practical constraints which the theorists have so far failed to recognize. But one must add three important challenges which responsible food aid managers have yet to take on.

\section{i Bureaucratic Management}

The most immediate is the challenge to the administrators which is very real: for organizations which have, in the case of WFP for over 25 years, learned to procure, transport and distribute food in kind, monetisation brings with it a wide range of new activities and responsibilities, which in turn means new. procedures, manuals, instructions, controls, reports and for all of these initially a dangerous lack of training and experience. Considering the inherently different nature of administering and auditing cash instead of food, monetisation adds to the traditional function of project food aid agencies a whole new dimension, for which there is so far no solid bureaucratic routine. To create one in the present environment (shrinking resources, often critical staff constraints, preoccupation with a wide-ranging general debate on the future of project food aid) is a formidable task indeed. This is the first aspect of the problem which the advocates of monetisation have so far largely ignored. Yet, it can be solved over time - the bureaucratic management of monetisation can be 'learned'.

\section{ii Absorptive Capacily}

The second challenge is absorptive capacity. In many developing countries, there are fewer easy outlets for project food aid sales than advocates of monetisation have assumed. Markets are covered either by commercial import or by concessional or grant programme food aid. Selling programme food aid is usually a straightforward transaction, made through established trade connections and friendly business partners, mostly for the purpose of balance-ofpayments aid and thus without much concern for local resale prices. Sometimes, low resale prices are even

of counterpart funds is set out in WFP (1983), WFP (1987a) and WFP (1987b)
This article represents the personal views of the author, not the official position of WFP.

2 WFP policy and experience with monetisation and the management 
Conditions under which MONETISATION is the preferred option

1. The objective of the project is a general income transfer, not specific food supplementation; where food supplementation is the objective, cash funds can be reliably expected to be transferred to food expenditures.

2. Targeting within households (e.g. to women or children) is possible using cash transfers.

3. Social traditions require remuneration in cash.

4. Food is available to buy: local food markets or distribution mechanisms (e.g. fair price shops) function, or can be expected to adjust or be established in response to increased purchasing power; there are no serious distortions in local food markets.

5. Government bureaucratic managerial capacity is adequate for deposit/transfer/expenditure/ auditing of cash funds; no particular risk of diversion of funds.

6. Additionality of cash payments and their targeting on the poor assured or possible to arrange without violating Government budgetary/fiscal policies or procedures.

7. Cash-supplementation of specific target groups (e.g. civil-service staff) acceptable; no particular dependency/phase-out problems that argue against cash; risk of undesirable taste changes through direct distribution of food.

8. Monetisation, i.e. arrangements for sale and deposit/programming/auditing of cash funds, more cost-effective than distribution in kind.
Conditions under which DISTRIBUTION IN

$K I N D$ is the preferred option

The project objective is an increase in food intake which will not result from cash transfers.

Targeting within households can only be successful with food.

Social traditions allow remuneration in kind.

Food is unavailable (drought, civil disturbance, inadequate logistics, seasonal shortage) or overpriced (traders making supranormal profits or not serving remote areas); and government interventions using food aid cannot improve the functioning of the market.

Government bureaucratic managerial capacity is more suited to handling food in kind than cash funds; risk of diversion of food less than of funds.

Additionality and targeting on the poor more easily assured for food than for cash, given Government budgetary/fiscal policies or procedures.

Government prefers food as a temporary addition (topping-up) to e.g. civil service salaries, rather than cash; food is preferred because it is easier to phase-out, particularly during structural adjustment programmes; no risk of taste changes through distribution of food.

The cost-effectiveness of direct distribution (overall administrative/logistical costs against net local value of food transferred) is more favourable than monetisation. intended by recipient governments as a form of general food subsidy, or in order to assure easy profits of state industries, with little regard to the disincentive effect on local farmers. In fact, most programme food aid donors do not care much for the counterpart funds. Monetisation is quite a different thing for donors of project food aid: they have to be concerned with local prices (in order to avoid disincentives and to maximize the level of generated funds), but they have less easy access to local markets. Government parastatals are understandably reluctant to handle ad-hoc, but usually small quantities of sometimes not standard commercial commodities, and they are even more reluctant to pay what the project donor may consider a reasonably fair price (i.e. more or less the c.i.f. price): programme aid donors may be waiting in the wings to oblige with much lower prices, unless they have already fully saturated the market needs (and have done so at a much more 
opportune time than the project food aid donor may have chosen, having had to coordinate his sale with the cash-requirements of his project). Private traders will be influenced by much the same considerations. In any event, as long as the price is not 'right', direct distribution of food will often appear as the more easily defensible alternative.

\section{iii The Self-Targeting Quality of Food}

But there is more to this rediscovery of the merits of direct food distribution. It has to do with a better understanding of food insecurity, and more deliberate targeting of project food aid on the food insecure. This is the third challenge. In a nutshell: where people are food insecure, this may be because they are powerless; powerless people, however, may be reachable more safely with food than with cash. It is this aspect of effective targeting that the monetisation debate has so far failed to address. With growing concern for targeting poverty alleviation as its most immediate objective, the much-claimed 'self-targeting' potential of food aid turns out to be a real advantage.

Take three practical examples, chosen from currently operational WFP projects:

Example 1: Labour-intensive drainage work in slums outside Lusaka/Zambia, targeted at the poorest women. Remuneration is entirely in food. Cash might, theoretically, seem preferable to the women, giving them a greater flexibility in expenditure. However, in the unanimous judgement of all project authorities, many women would not be allowed to manage cash earnings, which would be claimed by husbands or male heads of households.

Example 2: Building of rural water reservoirs (Hafirs) in Kordofan/Sudan. Work, mostly manual excavation and transport of earth, is carried out by men and women. Because of soaring food prices (due to drought), remuneration with family food rations is much preferred to cash.

Example 3: A school-lunch programme for primary schools in the arid and thinly populated areas of Namibia. Most of the schools could probably manage to procure the necessary maizemeal locally. However, given the near-total absence of banks, fairly large (and for local traditions quite exorbitant) amounts of money would have to be delivered, deposited, handled, and accounted for in cash, which school principals would be unwilling and probably unable to do. Delivery to them of food in kind is the only realistic option.

The list of examples can be lengthened and the range of the argument broadened (see Figure 1). Food distribution in kind can be practical for a great variety of reasons: certain low-status commodities may have an intended self-targeting effect; food may be physically unavailable in a project area which private traders will not reliably serve; inflation or unrealistic exchange rates may reduce the sales proceeds to unreasonably low levels; cash payments to beneficiaries may create unwarranted expectations of permanent entitlement more easily than food will; or the delivery systems for food (transport, storage, handling, accounting) although physically awkward, may correspond more closely to the existing administrative structures and skills of the project authorities than the handling of cash would; and they may correspond better also to the traditional perceptions of control, including, not least, control by the beneficiaries themselves. Indeed, control is a central theme of the debate: sound bureaucratic management, 'fair' pricing of sales, effective targeting of the counterpart funds - all involve control. And food is, under practical conditions in many developing countries, often more safely controlled than cash. It is, therefore, not really surprising that food aid agencies such as WFP prefer to continue in their traditional mode of operation, particularly in a field - alleviation of poverty and hunger - in which the needs are so great and the room for manoeuvre should therefore be wide enough.

\section{THE FUTURE CHALLENGE}

But is it surprising? The three examples given earlier in defence of the traditional approach also illustrate its limitations: high logistic costs, need for complex organizational back-up, and resulting from these, almost inevitably a small size of projects, too small and too isolated to make a significant impact. One can easily imagine each of the three projects on a much larger scale, if they were integrated components of a supportive social policy, which would rely on market mechanisms for targeting and in which the traditional 'self-targeting' quality of food would then lose its edge. In short, one could easily imagine the three projects being financed through programme food aid.

Thinking in this direction was particularly evident at the January 1991 IDS Workshop, with its strong leaning on the integration of food aid into the overall development strategy of the recipient countries (Maxwell and Owens ibid). Rather than targeting food in kind to the poor, or even creating counterpart funds for the financing of poverty projects, the workshop recommended 'budgetary dialogue' between donor and recipient, and resulting from it, the integration of food aid into the budgetary process for the sustained financing of poverty alleviation programmes, i.e. ultimately a new kind of enlightened programme aid. Targeted transfer of food in kind was seen by many participants as perhaps having some legitimacy as a humanitarian NGO-type operation, but it was no longer in their eyes a serious form of development assistance. 
As things stand, this position reflects more a future hope than the present reality, and those at the workshop who advocated it, had indeed little to show in the way of practical application. In theory, programme food aid may today be tuned better to macro-economic policies than it was in the past, but this requires a level and quality of political/administrative coordination which is in practice seldom achieved: common counterpart funds, for instance, although proven to be effective, require too high political and managerial efforts to have moved beyond the idea stage in more than a few cases. Programme food aid is not, or not yet, an effective instrument for the financing and manage ment of targeted poverty alleviation. To make it into such an instrument will require a more active involvement, financial and managerial, on the part of donors in the development and implementation of targeted poverty alleviation ('safety net') programmes; and it will require a stronger concern for household poverty alleviation on the part of governments. In fact, it sometimes looks as if both approaches, programme and project food aid, are today striving from different starting points towards the same goal: to contribute more effectively and in a more sharply targeted manner to poor people's food security. As long as the current programme food aid does not move clearly ahead of project food aid in this competition, the latter will continue to have a legitimate role and the only question is whether its effectiveness can be raised.

All parties agree that the effectiveness of project food aid should be raised. The traditional approach of distribution in kind is not wrong, but it is unnecessarily narrow, and this reduces the effectiveness of project food aid as a resource for improving food security. Targeting of selected foods on selected groups of beneficiaries is inevitably costly, and gets more so as the targeting improves in precision. Many traditional projects are from the point of cost-effectiveness, dubious. Apart from the sheer costs (which can be borne partly or in full, by donors), the traditional approach, with its dual line of resourcing and the resulting need for coordination between the two, makes extra claims on that scarcest of developing countries' resources - bureaucratic management. In this way it discriminates against the poorest countries with the weakest administrations - most of them cannot manage more than a few projects at a time, too small and scattered to raise food security on any scale. In short: insistence on direct distribution as the only delivery mechanism for project food aid limits the absorptive capacity of the developing countries for what can be a valuable and massively available resource for them. Drawing on the list of criteria proposed in Figure 1, project food aid is today, and indeed should be, limited to the type of situations described on the right of the list. Monetisation would open up new room for manoeuvre in situations of the type described on the left of the list.
This is the immediate and practical argument for monetisation. A second argument is more theoretical and speculative - it has to do with the changing philosophy of aid. Distribution of food in kind to selected beneficiaries is a highly interventionist approach and never entirely free of paternalistic overtones (here again, the three examples given earlier are probably cases in point). However, considering the growing distrust of development theorists for blueprint design, regulation and control, and their preference for market mechanisms as a potential tool even for household targeting, it may well be that the traditional approach of distribution in kind will be seen increasingly as going 'against the grain'. Project food aid agencies should prepare for this development by deliberately increasing the share of monetisation in their programmes as fast as they reasonably can. Provided the targeting can be assured, any transfer of project food aid management to the market should, in principle be considered as desirable, and no project food aid agency should allow itself to leave existing potential for monetisation unused. The rule should indeed be: 'Define the targeting criteria for alleviation of food-security - but then monetise as much as possible - distribute in kind as little as necessary'.

\section{PRACTICAL CONCLUSIONS}

What does this mean in practice? I see two areas for change, one immediate and one longer term.

The immediate concern should be to review the traditional projects, operational and in the pipeline, for potential monetisation more systematically than this is so far done, in the light of the three constraints - or challenges - outlined earlier. The conscious choice between the two alternatives, i.e. distribution in kind or monetisation, should become a routine element of project identification, design and operation, so that potential scope for monetisation is no longer overlooked. Admittedly, that scope will probably initially be smaller than the advocates of monetisation had hoped for: my prediction is that, if checked against one or the other of the criteria proposed (see Figure 1), distribution in kind will indeed turn out to be preferable in many of the current projects. But the test should nevertheless be made in all cases.

The second innovation is of a longer-term nature. Project food aid agencies should seek a new generation of projects, in which larger amounts of food aid are targeted on food-insecure households, but in ways in which monetisation, i.e. reliance on local markets, would support rather than jeopardize the effective targeting. Among the reasons which explain the selftargeting capacity of food is really a not-so-positive feature of the traditional projects, namely their small size and short or uncertain duration. They remain 
below the threshold which, for governments, would make the establishment of cash-targeting mechanisms worthwhile. The three examples given earlier for projects in which food is preferable to cash, illustrate this point.

What could this new generation of projects look like? One avenue that should be explored is that of much larger public work programmes, which, financed from food aid counterpart funds, would provide employment not to narrowly and ad-hoc selected target groups, but as part of a mainstream social policy, to more broadly defined poor and food-insecure groups of the population. The Maharashtra employment guarantee scheme comes to mind as an example in which the offer of employment is itself self-targeting rather than the wage good, which in this case is cash (Drèze 1991). Large-scale public works will probably be among those programmes in which cash funds derived from monetisation can be targeted on poor people most effectively and with the relatively greatest assurance of proper administration. They will also have the advantage that the costs of technical support and supervision could be financed from the same source, which in the case of the traditional food-for-work usually constitutes a severe constraint. In short, among the traditional approaches, cash-for-work programmes may hold the greatest potential for massive growth.

It seems to me, another avenue to be explored is the much more systematic use of local NGOs for the targeting of food aid to a great variety of human resources development activities. In many developing countries, the awareness of the need for a minimum of social services as a condition for healthy economic development seems to be growing at a time when the public financing and administrative capacity of this sector is weakening - structural adjustment itself seems to have this contradictory effect of bringing to light a legitimate need while withdrawing the means for meeting it. NGOs today appear to be developing into a force that can take on the function of public services, provided that governments create the policy environment in which NGOs can work. Where this is the case, food aid can be an important source of their financing.
Individual local NGOs are usually small and even short-lived. The task for food aid agencies would, therefore, be to assist in the establishment of umbrella organizations which would monitor the effectiveness of local NGOs and then channel assistance to them in a flexible way and according to their absorptive capacity. While the individual units of such an approach would be small, the overall volume of aid going to the social sector would definitely be much larger than it is today. To be manageable by NGOs, food aid would have to be largely monetised, but considering the poor and foodsecure target groups of NGOs, the food-security character of the food aid would be very largely guaranteed.

There are other avenues to be explored, including evidently the large field of food entitlement programmes. The problem here is that the position of donors, but beyond them of the international aid community, on targeted food subsidies is still ambivalent. Much research has been carried out on the theoretical parameters of such programmes, and some on their operational feasibility, but so far the decisive step of advocating the outside financing of major programmes has not beein taken. Obviously, unless an entitlement programme is very small, involvement in it is a difficult step for the donor to take, given the risk of open-endedness. However, personally I find it difficult to envisage a Third World in which targeted food subsidy programmes will not be needed in growing numbers, and if ever they have to be undertaken, food aid will be a natural resource base. Indeed, food aid is today, and will probably be in the future, the main aid source for massive income transfer to poor households.

Be that as it may, monetisation of food aid will become more of an issue as time goes on, and as long as programme food aid remains, as it now is, mostly directed to balance-of-payment assistance, project food aid will have to assume a greater role as a channel for targeted household income transfers. For this role, it will have to master monetisation. Quite possibly, project food aid well monetised can set examples and lead the way to greater effectiveness also of programme food aid.

\section{REFERENCES}

Drèze, J., 1991, 'Famine prevention', Disasters, No 3, September

Maxwell, S. and Owens, T., 1991, 'Commodity aid and counterpart funds in Africa', Discussion Paper 291, IDS, Sussex

World Bank and World Food Programme, 1991, Food Aid in sub-Saharan Africa: An Agenda for the 1990s, Washington DC and Rome
World Food Programme, 1983, 'Sales of grain to help meet the internal costs in least developed countries', $W F P / C F A / 15 / 18$, WFP, Rome

-1987a, 'Monetisation of WFP food aid', WFP/CFA 24/5, WFP, Rome, August

$-1987 \mathrm{~b}$, 'The management of funds generated by foodassisted projects', WFP/CFA 23/5, WFP, Rome, April 